\title{
Compensation of pulmonary function after upper lobectomy versus lower lobectomy
}

\author{
Kazuhiro Ueda, MD, ${ }^{\text {a }}$ Toshiki Tanaka, MD, ${ }^{\mathrm{a}}$ Masataro Hayashi, MD, ${ }^{\mathrm{a}}$ Tao-Sheng Li, MD, ${ }^{\mathrm{a}}$ \\ Takehiro Kaneoka, ${ }^{\mathrm{a}}$ Nobuyuki Tanaka, MD, ${ }^{\mathrm{b}}$ and Kimikazu Hamano, $\mathrm{MD}^{\mathrm{a}}$
}

Objective: Major lung resection may induce expansion of the remaining lung, accompanied by some gain in the
function of this lung; however, the impact of the site of resection on this compensatory response remains unclear.

\begin{abstract}
Methods: We measured computed tomography-based functional lung volume, representing normal lung attenuation ( -600 to -910 Hounsfield units), and spirometry-based lung function (forced expiratory volume in 1 second) preoperatively and 6 months postoperatively in patients with lung cancer and compared them between patients undergoing upper lobectomy $(\mathrm{n}=34)$ and patients undergoing lower lobectomy $(\mathrm{n}=26)$.
\end{abstract}

Results: We removed $17 \% \pm 4 \%$ of the functional lung volume by upper lobectomy and $27 \% \pm 5 \%$ by lower lobectomy $(P<.001)$. Postoperatively, the residual lung expanded by various degrees, accompanied by a proportionate gain in the residual lung function $(R=0.6, P<.001)$. This anatomic and functional compensation of the residual lung was more remarkable after lower lobectomy than after upper lobectomy $(P<.05)$. Consequently, the percentage loss of the functional lung volume after upper lobectomy $(10 \% \pm 10 \%)$ did not differ significantly from that after lower lobectomy $(9 \% \pm 12 \%, P=.6)$. Likewise, the percentage loss of lung function after upper lobectomy $(12 \% \pm 16 \%)$ did not differ significantly from that after lower lobectomy $(14 \% \pm 17 \%$, $P=.6)$.

Conclusions: Although the lower lobectomy implies greater resection than the upper lobectomy, lung function after lower lobectomy was not inferior to that after upper lobectomy because the compensatory response appeared more robust after lower lobectomy. (J Thorac Cardiovasc Surg 2011;142:762-7)

Pulmonary resection provides the only curative option for patients with localized lung cancer; however, it results in permanent loss of pulmonary function because the remaining lung cannot reproduce alveolar units to completely compensate for the lost lung tissue. This permanent loss of pulmonary function can compromise both quality of life and prognostic outcome. ${ }^{1}$ Thus, an accurate prediction of late postoperative pulmonary function, especially forced expiratory volume in 1 second $\left(\mathrm{FEV}_{1}\right)$, is crucial for patients undergoing major pulmonary resection.

Late postoperative $\mathrm{FEV}_{1}$ may be calculated not only by the extent of lung resection but also by the ability of the remaining lung to compensate for the lost lung tissue; the so-called compensatory lung response. ${ }^{2}$ The compensatory response of the remaining lung consists mainly of an

\footnotetext{
From the Division of Chest Surgery, ${ }^{\mathrm{a}}$ Department of Surgery and Clinical Science, and Division of Radiology, ${ }^{b}$ Department of Radiopathology and Science, Yamaguchi University Graduate School of Medicine, Ube, Yamaguchi, Japan. Disclosures: Authors have nothing to disclose with regard to commercial support. Received for publication Nov 1, 2010; revisions received March 15, 2011; accepted for publication April 19, 2011; available ahead of print June 16, 2011.

Address for reprints: Kazuhiro Ueda, MD, Department of Surgery and Clinical Science, Division of Chest Surgery, Yamaguchi University Graduate School of Medicine, 1-1-1 Minami-Kogushi, Ube, Yamaguchi, 755-8505, Japan (E-mail: kaueda@c-able.ne.jp). 0022-5223/\$36.00

Copyright $₫ 2011$ Published by Elsevier Inc. on behalf of The American Association for Thoracic Surgery

doi:10.1016/j.jtcvs.2011.04.037
}

increase in the anatomic lung volume, which until recently was attributed to hyperinflation of the individual alveolar duct. ${ }^{3}$ However, Ravikumar and colleagues ${ }^{4}$ and $\mathrm{Hsia}^{5}$ denied this notion on the basis of evidence obtained from radiologic assessment using high-resolution computed tomography (CT) of the remaining lung after contralateral pneumonectomy in adult foxhounds. They reported that the compensatory increase in the residual lung volume did not lead to the attenuation of lung density, but resulted in a substantial increase in the remaining lung volume of normal CT attenuation values. After contralateral pneumonectomy, each remaining lung lobe acted differently on the compensatory response: Most notably, the upper lobe acted on the compensatory response more remarkably than the lower lobe.

A compensatory response can be observed even in patients undergoing lobectomy or segmentectomy for lung cancer. Major lung resection resulted in some increase in the remaining lung volume of normal $\mathrm{CT}$ attenuation values ( -600 to -910 Hounsfield units [HU]), which was accompanied by a proportionate gain in the remaining lung function. ${ }^{6}$ In view of these findings, we speculated that patients may be more likely to benefit from the compensatory response after lower lobectomy than after upper lobectomy. In the present study, we correlated the structural change, as evaluated by quantitative $\mathrm{CT}$, to the functional change of the remaining lung after major lung resection for cancer. We then compared these structural-functional 


$$
\begin{aligned}
& \text { Abbreviations and Acronyms } \\
& \begin{aligned}
\mathrm{CT} & =\text { computed tomography } \\
\mathrm{FEV}_{1} & =\text { forced expiratory volume in } 1 \text { second } \\
\mathrm{FLV} & =\text { functional lung volume } \\
\mathrm{HU} & =\text { Hounsfield units } \\
3 \mathrm{D} & =3 \text {-dimensional }
\end{aligned}
\end{aligned}
$$

changes in patients who underwent upper lobectomy with those in patients who underwent lower lobectomy.

\section{PATIENTS AND METHODS \\ Patients}

This retrospective study was approved by the institutional review board of the Yamaguchi University School of Medicine. Consent for the study was waived. During the 5-year period from January 2003 to January 2008, 202 major lung resections were performed for clinical stage I lung cancer at Yamaguchi University School of Medicine. We analyzed 60 of these patients, for whom preoperative and late postoperative (6-12 months postoperatively) spirometry and entire thoracic CT data were available.

Operability was based on the existing guidelines for pulmonary resection. ${ }^{7}$ The criteria for resection included a partial pressure of arterial carbon dioxide less than $50 \mathrm{~mm} \mathrm{Hg}$, a mean pulmonary arterial pressure less than $30 \mathrm{~mm} \mathrm{Hg}$, and a calculated predicted postoperative $\mathrm{FEV}_{1}$ greater than 500 $\mathrm{mL}$. Patient data obtained preoperatively included age, sex, height, body weight, smoking habits, tumor location, site of resection, and spirometric variables. The patients' characteristics are summarized in Table 1. Thirty-four patients underwent upper lobectomy, and 26 patients underwent lower lobectomy, including 3 who underwent middle and lower lobectomy. The patients' characteristics in the upper versus lower lobectomy groups are shown in Table 1. The criteria of pulmonary emphysema were met in 10 patients, as described later. Diffuse interstitial lung infiltrates were seen in 5 patients, manifesting as pulmonary fibrosis in 3 and idiopathic interstitial pneumonitis in 2. No underlying lung diseases, including pneumoconiosis, old tuberculosis, or bronchial asthma, were detected clinically before surgery.

\section{Pulmonary Function Tests}

Preoperative spirometric variables were obtained within 1 month preoperatively and between 6 and 12 months postoperatively, including forced vital capacity and $\mathrm{FEV}_{1}$. The percentage of predicted $\mathrm{FEV}_{1}$ is expressed as the percentage of predicted values for age, gender, and height.

\section{Computed Tomography Scan}

CT scan was performed using a multidetector-row CT scanner. With the patient in the supine position, we obtained 2-mm high-resolution CT images of the entire lungs during a deep inspiratory breath-hold. We used a $512 \times 512$ matrix, 2-mm collimation, and a scan time of 1.0 seconds, at 120 to $130 \mathrm{kVp}$ and 220 to $230 \mathrm{~mA}$. This is a routine practice, and thus patients were not exposed to additional radiation for the purpose of measuring regional lung volume in this study.

Transaxial CT images were reconstructed with the lung algorithm. Threshold limits of -600 to $-910 \mathrm{HU}$ were applied to segment the entire lungs and to exclude soft tissues surrounding the lung and the large vessels, atelectasis, fibrosis, lung tumors, and hyperinflated areas within the lung. ${ }^{8-11}$ This radiologically defined lung volume is functional lung volume (FLV). ${ }^{8,9}$ Three-dimensional (3D) lung volume images representing lung contours, including lobar fissures, vasculatures, and volume, were created using imaging software (M900 QUADRA; Zio Soft K.K., Osaka, Japan) (Figure 1).
TABLE 1. Characteristics according to the resection site

\begin{tabular}{lcccc}
\hline \multicolumn{1}{c}{ Variables } & $\begin{array}{c}\text { Total } \\
(\mathbf{n = 6 0})\end{array}$ & $\begin{array}{c}\text { Upper } \\
\text { lobectomy } \\
(\mathbf{n = 3 4 )}\end{array}$ & $\begin{array}{c}\text { Lower } \\
\text { lobectomy } \\
(\mathbf{n = 2 6})\end{array}$ & $\boldsymbol{P}$ \\
\hline Age (y) & $68.0 \pm 8.4$ & $66.5 \pm 7.8$ & $69.9 \pm 8.7$ & .12 \\
Gender (M/F) & $48 / 12$ & $29 / 5$ & $19 / 7$ & .07 \\
BMI (kg/m $\left.{ }^{2}\right)$ & $21.7 \pm 3.4$ & $21.6 \pm 3.4$ & $21.9 \pm 3.5$ & .75 \\
Pack-year smoked & $39.2 \pm 44.0$ & $38.5 \pm 32.0$ & $40.2 \pm 48.0$ & .87 \\
FLV (L) & $4.81 \pm 1.08$ & $4.95 \pm 0.91$ & $4.63 \pm 1.25$ & .25 \\
FVC (L) & $3.05 \pm 0.41$ & $3.19 \pm 0.66$ & $2.89 \pm 0.18$ & .14 \\
FEV 1 (L) & $2.13 \pm 0.64$ & $2.30 \pm 0.69$ & $2.00 \pm 0.60$ & .10 \\
FEV $_{1} / \mathrm{FVC}(\%)$ & $71.7 \pm 11.9$ & $71.8 \pm 12.9$ & $71.5 \pm 9.6$ & .92 \\
FEV $_{1}(\%$ of & $84.0 \pm 21.2$ & $84.6 \pm 20.9$ & $83.4 \pm 21.6$ & .83 \\
$\quad$ predicted) & & & & \\
Emphysema & 10 & $4 *$ & $6 \dagger$ & .24 \\
IPF & 5 & 4 & 1 & .27 \\
\hline
\end{tabular}

$B M I$, Body mass index; $F L V$, functional lung volume as measured by chest computed tomography; $F V C$, forced vital capacity; $F E V_{l}$, forced expiratory volume in 1 second; $I P F$, idiopathic pulmonary fibrosis. Data are expressed as number or means \pm standard deviation. Lower lobectomy also includes middle and lower lobectomy $(\mathrm{n}=3)$. *Including 2 upper lobes with predominant emphysema. †Including 1 upper lobe with predominant emphysema.

\section{Image Interpretation and Data Analysis}

We diagnosed pulmonary emphysema by a low attenuation area $(<-910$ $\mathrm{HU})$ of $10 \%$ or more within the entire lung. To evaluate the regional lung volumes, regions of interest were placed over the lung areas to be resected by referring to shaded or transparent $3 \mathrm{D}$ lung models, as described previously. ${ }^{9}$ The 3D lung model can be freely rotated on the computer screen, and any portion of the lung can be removed from the screen by outlining that area directly on the 3D lung model, simulating a real pulmonary lobectomy. Throughout the procedures, the volume of the specific lung lobe was calculated automatically and displayed on the screen. We routinely measured the baseline FLV of the total lung and the lung to be resected on preoperative CT scans (Figure 1). We also measured the postoperative FLV of the total lung on CT scans taken 6 months postoperatively. It takes 15 to 20 minutes to obtain these volumetric variables per patient. Finally, we estimated $\mathrm{FEV}_{1}$ of the remaining lung on the basis of the regional distribution of the FLV because this quantitative CT-based method was statistically as accurate as the methods based on the pulmonary perfusion scanning. ${ }^{9,12,13}$ We substantially calculated the $\mathrm{FEV}_{1}$ of the remaining lung by the following equation: $\mathrm{FEV}_{1}$ of the remaining lung = preoperative $\mathrm{FEV}_{1}$ [1-(FLV of the resected lobe/total preoperative FLV)].

We correlated the postoperative FLV change to the $\mathrm{FEV}_{1}$ change of the remaining lung. These anatomic-functional changes were then compared between patients who underwent upper lobectomy and patients who underwent lower lobectomy.

\section{Compensatory Lung Response}

We defined compensatory lung response as a phenomenon in which the measured postoperative $\mathrm{FEV}_{1}$ and the measured postoperative FLV are both larger than one would expect according to baseline values and the estimated contribution of the lobe to be resected.

\section{Statistical Analysis}

The unpaired Student $t$ test was used to test relationships between discrete variables and continuous variables. The paired Student $t$ test was used to compare preoperative with postoperative values from the same patient. Values are expressed as means \pm standard deviation. The chi-square test was used to compare discrete variables. Linear regression analysis was used to test the relationship between the 2 continuous variables. 


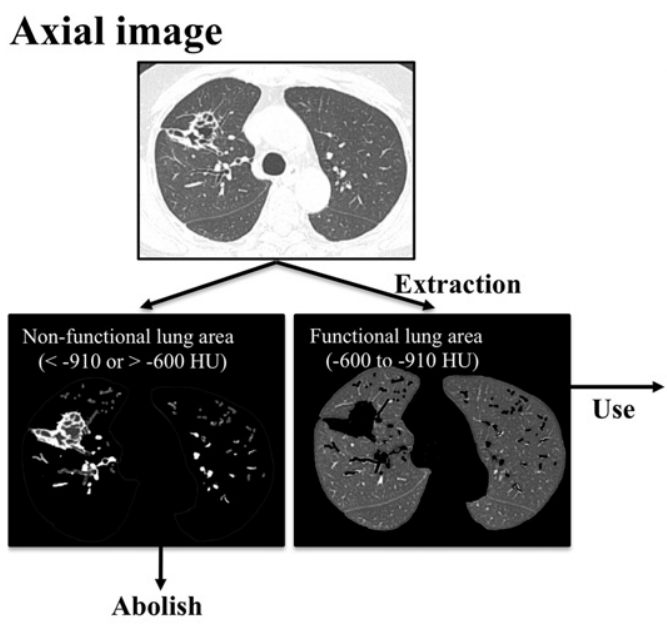

3D lung

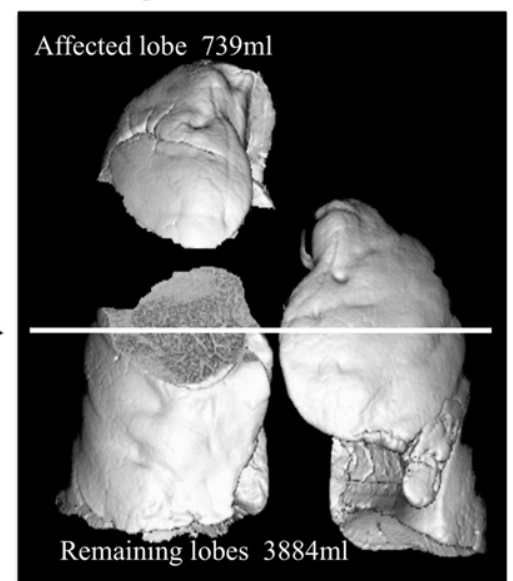

FIGURE 1. Measurement of FLV, which is obtained by summing the functional lung area ( -910 to $-600 \mathrm{HU})$. Naturally, functional lung area does not include the nonfunctional lung area $(<-910$ or $>-600 \mathrm{HU})$, such as emphysema, fibrosis, lung tumor, atelectasis, and large pulmonary vessels. FLV of the affected lobes and FLV of the remaining lobes are measured separately before operation. $H U$, Hounsfield units; 3D, 3-dimensional.

\section{RESULTS}

Table 1 shows preoperative pulmonary functional parameters. There were no significant differences in these parameters between the upper and lower lobectomy groups. Overall, we removed $21.0 \% \pm 6.8 \%(1.0 \pm 0.4 \mathrm{~L})$ of the FLV with each lobectomy. Postoperatively measured FLV is $115.0 \% \pm 15.8 \%$ of the estimated postoperative FLV. As a result, the net decrease of the FLV caused by lobectomy was only $9.5 \% \pm 10.9 \%$ of the preoperative FLV (Figure 2). Again, the postoperatively measured $\mathrm{FEV}_{1}$ was $111.0 \% \pm 22.2 \%$ of the estimated postoperative $\mathrm{FEV}_{1}$. As a result, the net decrease of the $\mathrm{FEV}_{1}$ after lobectomy was only $12.8 \% \pm 15.9 \%$ of the preoperative $\mathrm{FEV}_{1}$ (Figure 2). Figure 3 shows the correlation between the postoperatively measured FLV (percentage of estimated postoperative FLV) and the postoperatively measured $\mathrm{FEV}_{1}$ (percentage of estimated postoperative $\mathrm{FEV}_{1}$ ) (Figure 3).

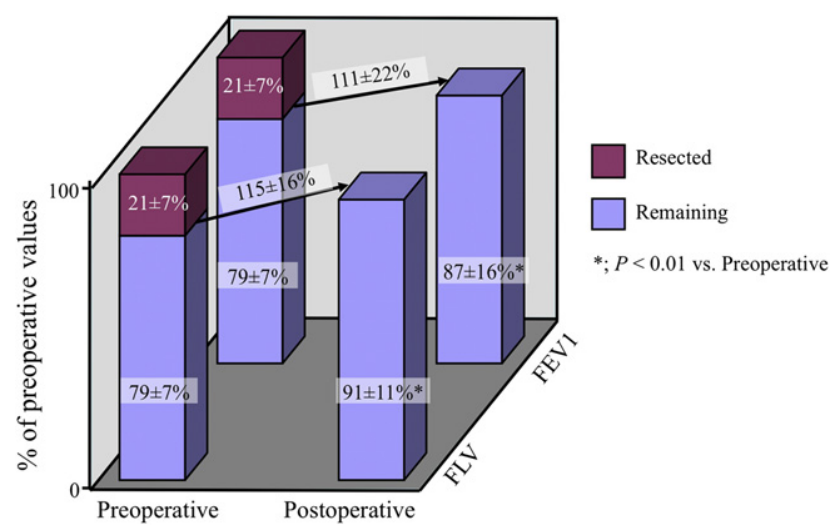

FIGURE 2. Postoperative change in FLV and $\mathrm{FEV}_{1}$ of the remaining lung after lobectomy. $F E V_{l}$, Forced expiratory volume in 1 second; FLV, functional lung volume.
Although both postoperatively measured FLV and FEV 1 differed from the estimated postoperative values by varying degrees, the postoperatively measured FLV (percentage of estimated) correlated significantly to the postoperatively measured $\mathrm{FEV}_{1}$ (percentage of estimated) $(\mathrm{Y}=0.85 \mathrm{X}+$ $13.1, R=0.604, P<.0001)$.

With special reference to the resection site, we removed $16.6 \% \pm 4.2 \%(0.8 \pm 0.2 \mathrm{~L})$ of the total FLV by performing an upper lobectomy and $26.8 \% \pm 5.0 \%(1.3 \pm 0.5 \mathrm{~L})$ by performing a lower lobectomy $(P<.0001$, Figure $4, A)$. Nevertheless, the net loss of the FLV, compared with the preoperative FLV, was $10.2 \% \pm 10.4 \%$ after upper lobectomy and only $8.6 \% \pm 11.8 \%$ after lower lobectomy (Figure $4, A$ ). The extent of loss between the 2 groups did not differ significantly $(P=.594)$. Likewise, the net loss of the $\mathrm{FEV}_{1}$, compared with the preoperative $\mathrm{FEV}_{1}$, was $11.7 \% \pm 15.5 \%$ after upper lobectomy and only $14.2 \%$ $\pm 16.7 \%$ after lower lobectomy (Figure $4, B$ ). The extent of loss between the 2 groups did not differ significantly $(P=.565)$. These results were not changed even when analysis was restricted to 52 patients undergoing single lobectomy and having no interstitial infiltrates: We removed $16.5 \% \pm 4.3 \%$ of the total FLV by performing upper lobectomy $(\mathrm{n}=30)$ and $25.9 \% \pm 4.3 \%$ by performing lower lobectomy ( $\mathrm{n}=22, P<.0001)$. Nevertheless, the net loss of the FLV, compared with the preoperative FLV, was $9.2 \%$ $\pm 10.2 \%$ after upper lobectomy and only $8.2 \% \pm 9.6 \%$ after lower lobectomy. The extent of loss between the 2 groups did not differ significantly $(P=.479)$. Likewise, the net loss of the $\mathrm{FEV}_{1}$, compared with the preoperative $\mathrm{FEV}_{1}$, was $10.4 \% \pm 15.8 \%$ after upper lobectomy and only $14.6 \% \pm 15.7 \%$ after lower lobectomy. The extent of loss between the 2 groups did not differ significantly $(P=.364)$. 


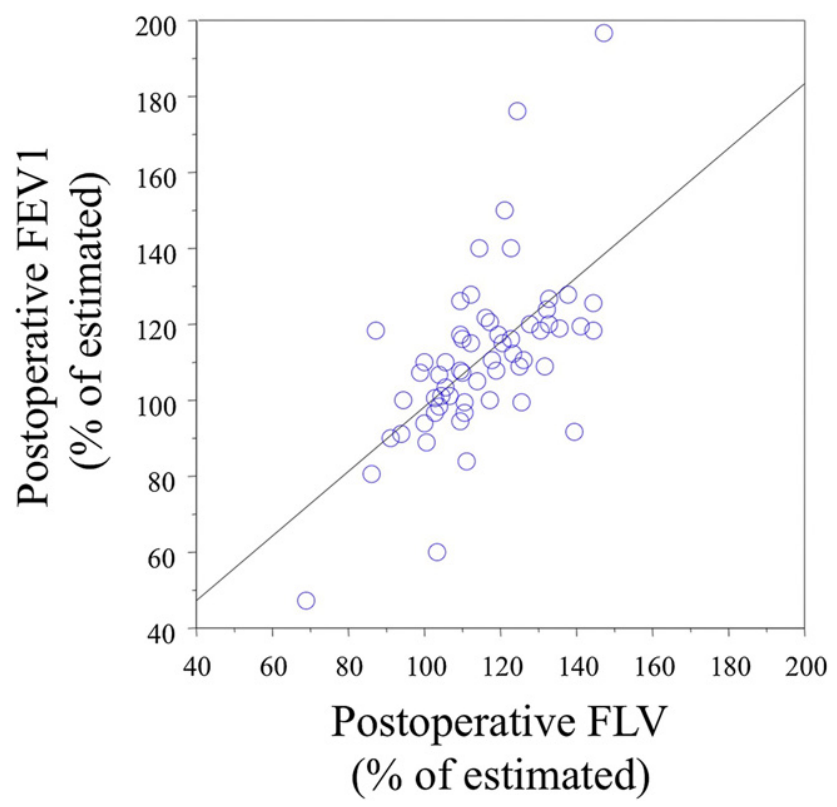

FIGURE 3. Correlation between postoperatively measured FLV ( $\%$ of estimated postoperative FLV) and postoperatively measured $\left.\mathrm{FEV}_{1}\right)(\%$ of estimated postoperative $\mathrm{FEV}_{1}$. Significant correlation between the parameters is noted $(\mathrm{Y}=0.85 \mathrm{X}+13.1, R=0.604, P<.0001)$. $F E V_{l}$, Forced expiratory volume in 1 second; $F L V$, functional lung volume.

Postoperative complications developed after upper lobectomy in 3 patients, as atrial fibrillation in 1 patient and prolonged air leak for $>10$ days in 2 patients; and after lower lobectomy in 2 patients, as atrial fibrillation in 1 patient and lobar atelectasis in 1 patient. These complication rates did not differ significantly $(P=.26)$.

With respect to pulmonary emphysema, $7.1 \% \pm 8.0 \%$ (range, $0.1 \%-33 \%$ ) of the total lung area was identified as the low attenuation area $(<-910 \mathrm{HU})$ in each patient. Figure 5 shows the correlation between the postoperatively measured FLV (percentage of estimated postoperative FLV) and the postoperatively measured $\mathrm{FEV}_{1}$ (percentage of estimated postoperative $\mathrm{FEV}_{1}$ ), with special reference to the presence $(n=10)$ or absence $(n=50)$ of pulmonary emphysema. Although the postoperatively measured FLV (percentage of estimated postoperative FLV) for patients with pulmonary emphysema was comparable to that for patients without pulmonary emphysema $(117.8 \% \pm 11.8 \%$ vs $114.4 \% \pm 16.5 \%, P=.53)$, the postoperatively measured $\mathrm{FEV}_{1}$ (percentage of estimated postoperative $\mathrm{FEV}_{1}$ ) for patients with emphysema was significantly greater than that for patients without pulmonary emphysema $(126.8 \% \pm$ $22.9 \%$ vs $107.9 \% \pm 20.9 \%, P=.0129$; Figure 5 ).

\section{DISCUSSION}

In 1980, Ali and colleagues ${ }^{3}$ reported that the compensatory inflation of the remaining lung lobe after lobectomy for lung cancer was accompanied by increased pulmonary ventilation and perfusion of the remaining lung lobe, as evaluated by scintigraphy, as well as improved global ventilation capacity, as evaluated by spirometry. More recently, Hsia $^{5}$ suggested that the compensatory expansion of the remaining lung is not simply a consequence of hyperinflation of the preexisting alveolar septal tissue, but that it is accompanied by some increase in the vital lung tissue, on the basis of microscopic and radiologic evaluation of the adult dog lung morphology. ${ }^{2,4}$ This compensatory lung response consists of the cooperation of existing alveolar-capillary reserves, remodeling of existing air conduct, and an increase in functioning lung tissue. In the physiologic state, vital lung tissue represents the $\mathrm{CT}$ attenuation value of normal lung parenchyma; therefore, the FLV used in the present study may be a reliable surrogate to measure the compensatory lung response.

We formerly measured FLV to compare the compensatory response after lobectomy with that after segmentectomy. ${ }^{6}$ The FLV of the ipsilateral remaining lung lobe and the contralateral lung increased significantly after surgery, suggesting that the compensatory response of the contralateral lung after lobectomy may improve remaining lung function postoperatively. Moreover, we found that the compensatory response was more prominent after lobectomy than after segmentectomy. ${ }^{6}$ This result is somewhat similar to that in the present study in that the compensatory lung response was enhanced after the resection of a relatively larger part of the lung than after the resection of a smaller section. This notion is consistent with the findings in the previous report: The principal stimulating factor for compensatory lung response, among the various factors reported, is physical strain after pulmonary resection, which is imposed in relation to the extent of lung resection and acts on stretching the remaining lung. ${ }^{2}$

Whether lower lobectomy promotes the refractory improvement of remaining lung function more than upper lobectomy remains controversial. ${ }^{14,15}$ One possible explanation is that the remaining lung function is improved not only by the compensatory response but also by the lung volume reduction effect in patients with pulmonary emphysema. ${ }^{16-21}$ To distinguish the compensatory response from the volume reduction effect, combined functional-anatomic assessment of the remaining lung is essential. Figure 5 shows the correlation between the postoperatively measured FLV (percentage of estimated postoperative FLV) and the postoperatively measured $\mathrm{FEV}_{1}$ (percentage of estimated postoperative $\mathrm{FEV}_{1}$ ), with special reference to the presence $(\mathrm{n}=10)$ or absence $(n=50)$ of pulmonary emphysema. Figure 5 suggests that in some patients with emphysema, the remaining lung function improves remarkably because of the volume reduction effect, but without corresponding gain in the FLV of the remaining lung. Because the postoperatively measured FLV (percentage of estimated postoperative FLV) did not differ between the patients with and the patients without pulmonary 

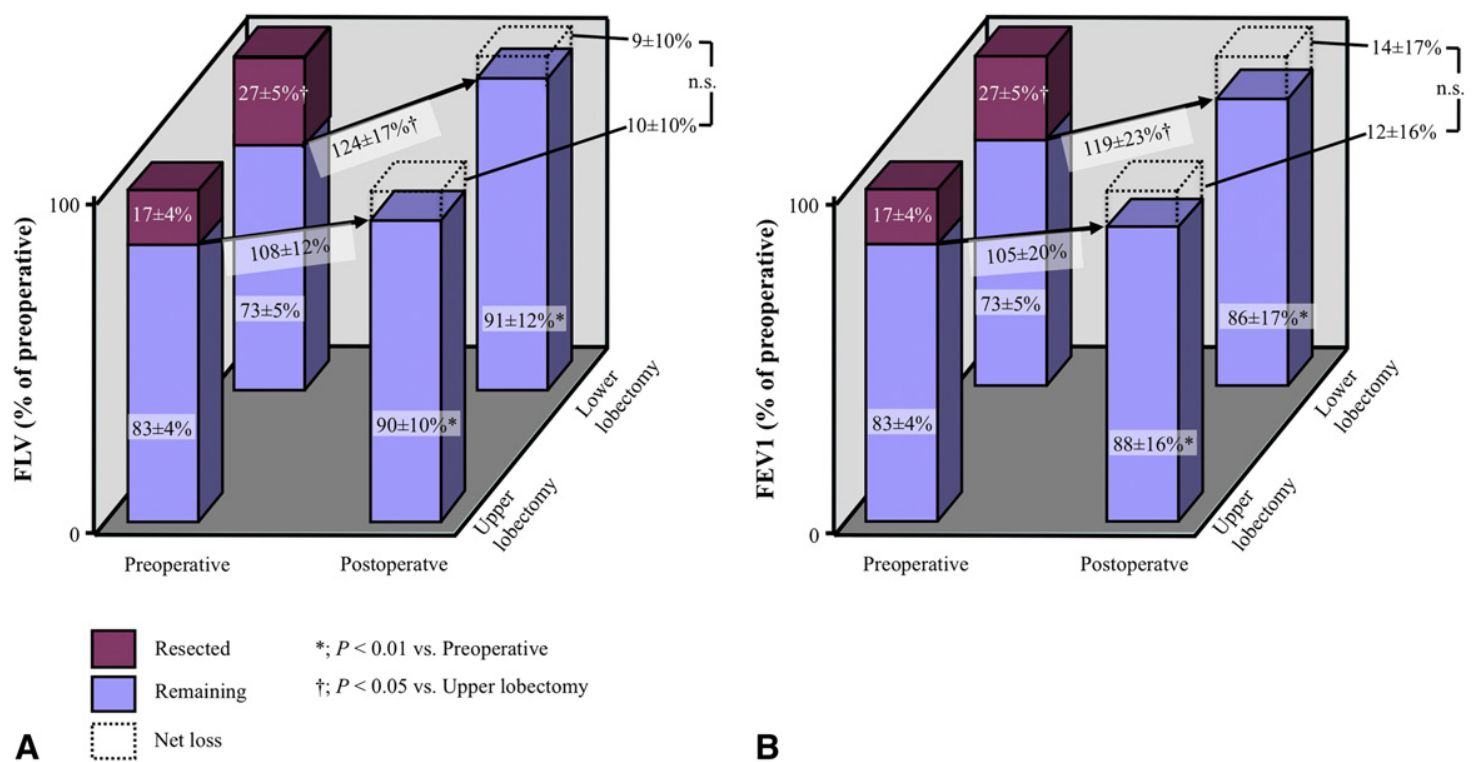

FIGURE 4. Postoperative change in FLV (A) and $\mathrm{FEV}_{1}$ (B) of the remaining lung after upper lobectomy versus that after lower lobectomy. $F E V_{l}$, Forced expiratory volume in 1 second; $F L V$, functional lung volume.

emphysema, we do not think that the presence of pulmonary emphysema affected our results.

Measuring the FLV of the affected lobe and the FLV of the remaining lobes separately may contribute to an accurate estimation of the anatomic-functional loss after lung lobectomy because the diseased lung area, especially the

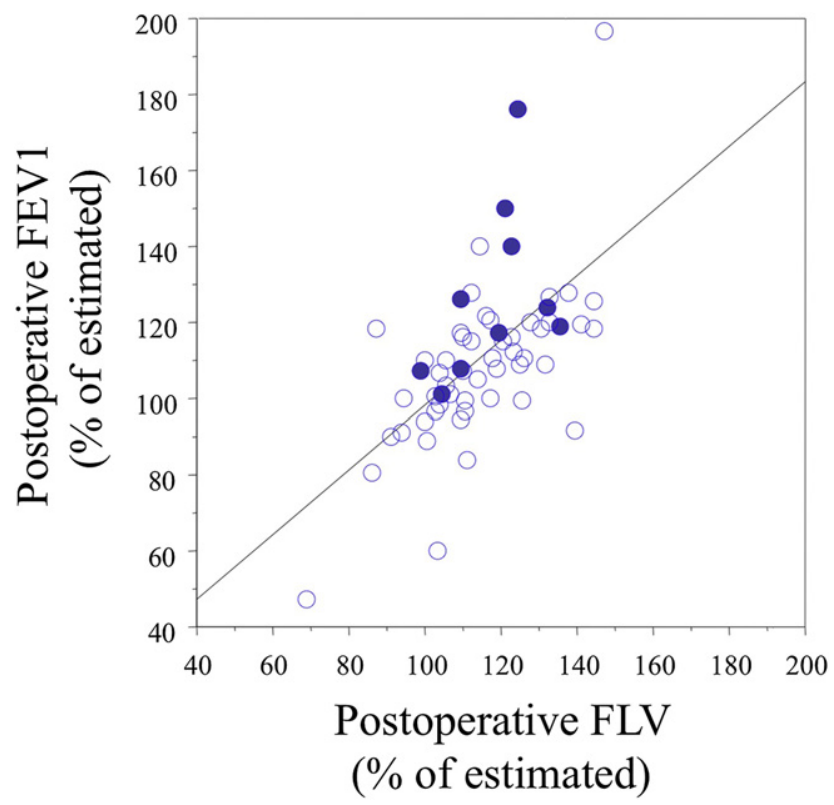

FIGURE 5. Correlation between postoperatively measured FLV ( $\%$ of estimated postoperative FLV) and postoperatively measured $\mathrm{FEV}_{1}$ (\% of estimated postoperative FEV1), with special reference to the presence (solid circles) or absence (open circles) of pulmonary emphysema. $F E V_{l}$, Forced expiratory volume in 1 second; $F L V$, functional lung volume. emphysematous area, is often distributed heterogeneously to either the upper lobe or the lower lobe, altering the functional roles of these lobes. In our previous study, we accurately predicted early postoperative lung function in patients undergoing major pulmonary resection by measuring the FLV of the lung to be resected and the FLV of the lung to be preserved, individually. ${ }^{9}$ The utility of measuring the regional FLV was also verified by the preceding study: The diseased lung area involved by fibrosis, atelectasis, or emphysema, depicted as the unmasked area on CT, corresponded well with the pulmonary perfusion defects on scintigraphy. ${ }^{22}$

As mentioned before, lower lobectomy acted on the compensatory response more than upper lobectomy did, because relatively greater lung resection is considered to promote compensatory response of the remaining lung. Another possible explanation could be that the upper lobes have more alveolar-capillary reserves than the lower lobe to be recruited postoperatively, although we cannot pathologically or functionally measure the reserved functional tissues in an individual lobe before pulmonary resection. Finally, we speculate that cranial transposition of the remaining lower lobe after upper lobectomy may adversely affect the remodeling of the existing air conduct, which is the necessary pathologic basis of compensatory response. To clarify our speculation, we must make a radiologicbased observation of the bronchial lumen of the remaining lung lobe after its cranial transposition.

\section{Study Limitations}

A limitation of the present study is that we could analyze only a proportion of patients $(60 / 202)$ who had received 
lobectomy for stage I lung cancer during the study period because we did not routinely perform pulmonary function tests and thin-section thoracic CT late postoperatively (6-12 months after operation). Although we carefully selected all patients with available data on pulmonary function, chest CT, and follow-up, our study may include a risk of selection bias.

Another limitation is that we did not evaluate pulmonary perfusion and diffusion capacity, although previous reports support our suggestion regarding compensatory response. Ali and colleagues ${ }^{3}$ performed ventilation/perfusion scintigraphy and pulmonary function tests before and after lung lobectomy, and found that pulmonary perfusion, ventilation, and $\mathrm{FEV}_{1}$ improved synchronously toward the late postoperative period. ${ }^{3}$ In addition, Brunelli and colleagues $^{23}$ found that the diffusion capacity improved time-dependently in accordance with the increase in the $\mathrm{FEV}_{1}$ after major lung resection for cancer. They reported that both late postoperative (3 months postoperatively) $\mathrm{FEV}_{1}$ and diffusion capacity were significantly higher than the estimated $\mathrm{FEV}_{1}$ and diffusion capacity. These data may suggest that postoperative increase in the remaining lung volume is not a simple volume change but is accompanied by a proportionate gain in the pulmonary perfusion, ventilation, and gas exchange capacity.

\section{CONCLUSIONS}

We evaluated late postoperative lung anatomicfunctional change in patients undergoing major lung resection because late postoperative pulmonary function represents their real pulmonary functional reserve and may determine their eventual quality of life. Poor compensatory response of the remaining lung was indeed associated with the progression of breathlessness or respiratory failure, especially in heavy smokers. Although the lower lobectomy implies greater resection than the upper lobectomy, we found that lung function after lower lobectomy was not inferior to that after upper lobectomy because the compensatory response appeared more robust after lower lobectomy.

\section{References}

1. Hole DJ, Watt GC, Davey-Smith G, Hart CL, Gillis CR, Hawthorne VM. Impaired lung function and mortality risk in men and women: findings from the Renfrew and Paisley prospective population study. BMJ. 1996;313:711-5.

2. American Thoracic Society. American Thoracic Society Workshop Document. Mechanisms and limits of induced postnatal lung growth. Am J Respir Crit Care Med. 2004;170:319-43.

3. Ali MK, Mountain CF, Ewer MS, Johnston D, Haynie TP. Predicting loss of pulmonary function after pulmonary resection for bronchogenic carcinoma. Chest. 1980;77:337-42.
4. Ravikumar P, Yilmaz C, Dane DM, Johnson RL Jr, Estrera AS, Hsia CC. Regional lung growth following pneumonectomy assessed by computed tomography. J Appl Physiol. 2004;97:1567-74.

5. Hsia CCW. Quantitative morphology of compensatory lung growth. Eur Respir Rev. 2006;15:101:148-56.

6. Ueda K, Tanaka T, Hayashi M, Li T-S, Tanaka N, Hamano K. Computed tomography-defined functional lung volume after segmentectomy versus lobectomy. Eur J Cardiothorac Surg. 2010;37:1433-7.

7. Beckles MA, Spiro SG, Colice GL, Rudd RM, American College of Chest Physicians. The physiologic evaluation of patients with lung cancer being considered for resectional surgery. Chest. 2003;123:105S-14.

8. Wu MT, Pan HB, Chiang AA, Hsu HK, Chang HC, Peng NJ, et al. Prediction of postoperative lung function in patients with lung cancer: comparison of quantitative CT with perfusion scintigraphy. AJR Am J Roentgenol. 2002;178:667-72.

9. Ueda K, Tanaka T, Li T-S, Tanaka N, Hamano K. Quantitative computed tomography for the prediction of pulmonary function after lung cancer surgery: a simple method using simulation software. Eur J Cardiothorac Surg. 2008;16:159-63.

10. Lamers RJ, Thelissen GR, Kessels AG, Wouters EF, van Engelshoven JM. Chronic obstructive pulmonary disease: evaluation with spirometrically controlled CT lung densitometry. Radiology. 1994;193:109-13.

11. Kinsella M, Muller NL, Abboud RT, Morrison NJ, DyBuncio A. Quantitation of emphysema by computed tomography using a "density mask" program and correlation with pulmonary function tests. Chest. 1990;97:315-21.

12. Ohno Y, Koyama H, Nogami M, Takenaka D, Matsumoto S, Yoshimura M, et al Postoperative lung function in lung cancer patients: comparative analysis of predictive capability of MRI, CT, and SPECT. AJR Am J Roentgenol. 2007;189: 400-8.

13. Yoshimoto K, Nomori H, Mori T, Kobayashi H, Ohba Y, Shibata H, et al. Prediction of pulmonary function after lung lobectomy by subsegments counting, computed tomography, single photon emission computed tomography and computed tomography: a comparative study. Eur J Cardiothorac Surg. 2009;35:408-13.

14. Sekine Y, Iwata T, Chiyo M, Yasufuku K, Motohashi S, Yoshida S, et al. Minima alteration of pulmonary function after lobectomy in lung cancer patients with chronic obstructive pulmonary disease. Ann Thorac Surg. 2003;76:356-61.

15. Kushibe K, Takahama M, Tojo T, Kawaguchi T, Kimura M, Taniguchi S. Assessment of pulmonary function after lobectomy for lung cancer-upper lobectomy might have the same effect as lung volume reduction surgery. Eur J Cardiothorac Surg. 2006;29:886-90.

16. Jubran A, Laghi F, Mazur M, Parthasarathy S, Garrity ER Jr, Fahey PJ, et al Partitioning of lung and chest-wall mechanics before and after lung volume reduction surgery. Am J Respir Crit Care Med. 1998;158:306-10.

17. Sciurba FC, Rogers RM, Keenan RJ, Slivka WA, Gorcsan J 3rd, Ferson PF, et al. Improvement in pulmonary function and elastic recoil after lung-reduction surgery for diffuse emphysema. N Engl J Med. 1996;334:1095-9.

18. Laghi F, Jubran A, Topeli A, Fahey PJ, Garrity ER Jr, de Pinto DJ, et al., Loyola/ Hines Lung Volume Reduction Surgery Research Group. Effect of lung volume reduction surgery on diaphragmatic neuromechanical coupling at 2 years. Chest. 2004; 125:2188-95.

19. Carretta A, Zannini P, Puglisi A, Chiesa G, Vanzulli A, Bianchi A, et al. Improvement in pulmonary function after lobectomy for non-small cell lung cancer in emphysematous patients. Eur J Cardiothorac Surg. 1999;15:602-7.

20. DeRose JJ Jr, Argenziano M, El-Amir N, Jellen PA, Gorenstein LA, Steinglass KM, et al. Lung reduction operation and resection of pulmonary nodules in patients with severe emphysema. Ann Thorac Surg. 1998;65:314-8.

21. Korst RJ, Ginsberg RJ, Ailawadi M, Bains MS, Downey RJ, Rusch VW, et al. Lobectomy improves ventilatory function in selected patients with severe COPD Ann Thorac Surg. 1998;66:898-902.

22. Sudoh M, Ueda K, Kaneda Y, Jinbo M, Li T-S, Suga K, et al. Breath-hold singlephoton emission tomography and computed tomography for predicting residual pulmonary function in patients with lung cancer. J Thorac Cardiovasc Surg. 2006;131:994-1001.

23. Brunelli A, Refai M, Salati M, Xiumé F, Sabbatini A. Predicted versus observed FEV1 and DLCO after major lung resection: a prospective evaluation at different postoperative periods. Ann Thorac Surg. 2007;83:1134-9. 